\title{
AS EXPERIÊNCIAS DE ESCOLARIZAÇÃO DOS SUJEITOS JOVENS E ADULTOS PARTÍCIPES DAS AÇÕES DO PEI/MOBRAL NO SERTÃO DE ALAGOAS
}

\author{
Marinaide Freitas ${ }^{1}$ \\ Jailson Costa da Silva ${ }^{2}$ \\ Andresso Marques Torres ${ }^{3}$
}

\section{RESUMO}

Este artigo narra as experiências de escolarização dos sujeitos jovens e adultos partícipes das ações do Programa de Educação Integrada (PEI), do Mobral, no sertão de Alagoas, especificamente na cidade de Santana do Ipanema, entre os anos de 1973 a 1985, e resulta de pesquisa realizada no período de 2019-2020. Investigou, após mais de 40 anos, as contribuições das práticas do PEl para a construção dos percursos escolares, e para tanto, trilhamos os pressupostos teórico-metodológicos da História Oral, por meio de entrevistas temáticas com 2 interlocutores, que se constituíram nas fontes orais, e também lançamos mão de documentos garimpados nos órgãos

1 Doutora em educação. Professora da Universidade Federal de Alagoas (UFAL) do Programa de Pós-Graduação em Educação Brasileira (PPGE) e do curso de Pedagogia. Coordenadora do Núcleo de Estudo, Pesquisa e Extensão sobre Alfabetização (Nepeal), Cedu/Ufal. Membro do GT 18 - Educação de Pessoas Jovens e Adultos da Anped e também, membro do Fórum Alagoano de Educação de Jovens e Adultos (FAEJA). ORCID: https://orcid.org/0000-0003-3659-4165 E-mail: marinaide.queiroz@cedu.ufal.br

2 Doutor em Educação. Professor da Instituto Federal de Alagoas (IFAL) do curso de licenciatura em Física. Integrante do Fórum Alagoano de Educação de Jovens e Adultos (FAEJA). Membro da Associação Nacional de Pós-Graduação e Pesquisa em Educação (ANPEd) - GT-18. Líder do Grupo Interdisciplinar de Pesquisas em Educação de Jovens e Adultos (GIPEJA/IFAL/CNPq). ORCID: https://orcid.org/0000-0001-5078-3603. E-mail: jailson.costa@ifal.edu.br

${ }^{3}$ Doutorando e Mestre em Educação pela Universidade Federal de Alagoas (PPGE/Ufal). Licenciado em Pedagogia. Membro do Grupo de Pesquisa Multidisciplinar em Educação de Jovens e Adultos - Multieja/CNPq. Desenvolve pesquisa no campo da História e Memória da Educação, com ênfase nas experiências de escolarização dos sujeitos jovens e adultos, sob enfoque teórico-metodológico da História Oral. ORCID: https://orcid.org/0000-0002-3521-7811. E-mail: andressotorres@hotmail.com 
oficiais locais, bem como no Acervo Digital do Centro de Referência e Memória da Educação Popular e de Jovens e Adultos, pertencentes à Universidade do Estado do Rio de Janeiro (Uerj). Por meio das narrativas foi possível compreender que, diante do contexto social da época (1970-1980), entrecortado pela sobrevivência, os sujeitos se apropriaram da "oportunidade" de acesso à escola, que se abria para eles naquele momento, e conseguiram mediante movimentos pendulares, permanecer, desafiando, assim, os marcadores sociais que tentavam conformá-los a uma ordem em que prevalecia as injustiças, especificamente a negação do direito de estudar.

Palavras-chave: PEI. Mobral. Jovens e Adultos. Sertão de Alagoas.

\section{THE SCHOOLING EXPERIENCES OF YOUNG AND ADULT PARTICIPANTS OF THE PEI/MOBRAL PRACTICES IN THE SERTÃO OF ALAGOAS ANDRAGOGY}

\section{ABSTRACT}

This paper narrates the schooling experiences of young and adult subjects who participated in the actions of the Integrated Education Program (PEI) in the Mobral program, at the Sertão of Alagoas, specifically in the city of Santana do Ipanema, between the years 1973 and 1985, and results from research conducted in the period of 20192020. After more than 40 years, the contributions of the PEI practices to the construction of schooling paths were investigated. To do so, we followed the theoretical and methodological assumptions of Oral History, through thematic interviews with 2 interlocutors, who were the oral sources, and we also took advantage of documents found in the local official offices, as well as in the Digital Collection of the Reference and Memory Center of Popular and Youth and Adult Education, belonging to the State University of Rio de Janeiro - UERJ. Through the narratives it was possible to understand that facing of the social context of the time (1970-1980), interspersed with survival narratives, the subjects took advantage of the "opportunity" to access school, which was open to them at that time, and managed, through commuting movements, to stay on, challenging the social context 
that tried to settle them in an unfair system - a one that denials the right to study.

Keywords: PEl. Mobral. Young People and Adults. Sertão of Alagoas.

\section{LAS EXPERIENCIAS DE ESCOLARIZACIÓN DE LOS SUJETOS JÓVENES Y ADULTOS PARTICIPANTES DE LAS ACCIONES DE PEI/MOBRAL EN EL SERTÓN DE ALAGOAS}

\section{RESUMEN}

Este artículo narra las experiencias de escolarización de los sujetos jóvenes y adultos participantes de las acciones del Programa de Educación Integrada - PEl, de Mobral, en el sertón de Alagoas, específicamente en la ciudad de Santana do Ipanema, entre los años 1973 a 1985, y resulta de la investigación realizada en el periodo de 2019-2020. Investigó, luego de más de 40 años, las contribuciones de las prácticas del PEI en la construcción de las trayectorias escolares, y para tal, nos adentramos en los presupuestos teórico-metodológicos de la Historia Oral, por medio de entrevistas temáticas con 2 interlocutores, que se constituyeron en fuentes orales, y también tomamos documentos sellados en los órganos oficiales locales, además del Acervo Digital do Centro de Referência e Memória da Educação Popular e de Jovens e Adultos, pertenecientes a la Universidad del Estado de Rio de Janeiro - UERJ. Por medio de las narrativas se hizo posible comprender que, frente al contexto social de la época (1970-1980), entrecortado por la sobrevivencia, los sujetos se apropiaron de la "oportunidad" de acceso a la escuela, que se abría para ellos en aquel momento, y lograron, mediante movimientos pendulares, permanecer, desafiando, de esta forma, los determinantes sociales que intentaban conformarlos con una orden donde prevalecían las injusticias, específicamente la negación del derecho a estudiar.

Palabras clave: PEI. Mobral. Jóvenes y adultos; Sertón de Alagoas. 


\section{INTRODUÇÃO}

Este trabalho resulta de uma pesquisa realizada no âmbito do Programa de Pós-Graduação em Educação (PPGE), da Universidade Federal de Alagoas (UFAL), entre os anos 2019-2020, no contexto do Grupo de Pesquisa Multidisciplinar em Educação de Jovens e Adultos (Multieja ${ }^{4} / \mathrm{CNPq}$ ) em articulação com o Centro de Referência e Memória da Educação Popular e de Jovens e Adultos (CReMEJA/UERJ). E buscou compreender, após mais de 40 anos, as experiências de escolarização dos sujeitos sertanejos alagoanos partícipes das ações do Programa de Educação Integrada (PEI) ${ }^{5}$ do Movimento Brasileiro de Alfabetização (Mobral) ${ }^{6}$, criado em 1967 pelo governo autoritário no âmbito da educação de adultos, implementado apenas em 1970, com o Programa de Alfabetização Funcional (PAF), que perdurou até 1985. O Movimento tinha como motivação impedir o alargamento da participação popular, "[...] por oposição e como alternativa aos movimentos sociais e educacionais inspirados na pedagogia de Paulo Freire" (FERRARO, 2009, p. 110).

Para o governo repressor daquele momento histórico, a alfabetização de adultos fazia sentido porque o desenvolvimento do

${ }^{4}$ Grupo de Pesquisa cadastrado no Diretório do CNPq, que agrega professores da educação básica do município de Maceió, da Ufal, do Ifal, graduandos, bolsistas de Iniciação Científica, mestrandos, doutorandos e pós-doutorandos, sendo lócus privilegiado para a formação inicial e continuada dos seus membros, e também vem realizando atividades como: cursos de curta duração; ciclos de palestras abertos ao público em geral; seminários temáticos; palestras nas escolas, dentre outras, e possui entre seus eixos de investigação, as seguintes "raízes Rizomáticas": Educação e Linguagem; História e Memória da EJA; Formação de Professores; Cotidianos e Culturas Organizacionais Escolares; Permanência Escolar e Proeja.

${ }^{5}$ O PEl foi o segundo Programa do Mobral, criado em 1973, e tinha como objetivo ofertar o ensino primário, num tempo de 12 meses, para os sujeitos tanto egressos do Programa de Alfabetização Funcional, quanto para as pessoas das comunidades que não tinham concluída esta etapa da escolarização na época.

${ }^{6}$ O Mobral nasceu como Fundação amparada pela Lei n. 5.379 de 15 de dezembro de 1967. Era originalmente financiado por recursos provenientes da Loteria Esportiva e da indicação de até $2 \%$ do Imposto de Renda devido por pessoas jurídicas. Em momento posterior, seus recursos limitam-se ao Imposto de Renda, nas mesmas regras anteriores, e implantou os seguintes Programas: Alfabetização Funcional (PAF); Educação Integrada (PEI), Autodidatismo, Mobral Cultural, Educação para o Trabalho, Educação Comunitária para a Saúde, e o Projeto Educação Pré-escolar. Foi extinto em 1985, juntamente com o fim da ditadura civil-militar. 
país, com a entrada de multinacionais, exigia mão de obra capaz de dominar, no mínimo, técnicas básicas de leitura e escrita; para que pudessem se pôr em acordo com ditames internacionais quanto à redução do analfabetismo entre os trabalhadores, o que se resolvia com propostas curtas de alfabetização. A premência de elevação do nível de escolaridade dos sujeitos, como direito humano ficava subsumida às exigências do mercado de trabalho, que as multinacionais abriam no país, em troca de muitos benefícios fiscais.

Estava instaurada a ditadura, fruto de uma coalizão civil e militar. Confirmou-se com a ascensão de um novo bloco no poder que envolvia "[...] a articulação entre o conjunto das classes dominantes, a exemplo a burguesia industrial e financeira nacional e internacional, [...] bem como uma camada (de caráter civil) de intelectuais e tecnocratas" (GERMANO, 2011, p. 17); motivados a impedir o alargamento da participação popular.

A pesquisa partiu da seguinte problematização: Como os sujeitos jovens e adultos sertanejos experienciaram as ações educacionais implementadas pelo Mobral, no que se refere à continuidade dos estudos? Como questões secundárias, buscamos entender: Quem são os sujeitos egressos do PEl/Mobral? Que configurações familiares estavam imersos? Que sentidos atribuíram à escolarização num contexto entrecortado pela sobrevivência, e numa época em que a escola não se constituía enquanto direito?

Entendendo as experiências a partir dos postulados teóricos do filósofo Jorge Larrosa (2016) para quem a experiência é tudo aquilo que nos passa, nos toca e, ao mesmo tempo nos acontece, o que interpretamos como os acontecimentos que fizeram sentidos para os sujeitos sertanejos, e que depois de quase cinco décadas, relembram com uma força narrativa muito forte. Porque esta é uma das características precípuas das narrativas, ou seja, depois de muito tempo ainda são possíveis de serem desenvolvidas (BENAJMIN, 1994), contendo muitos elementos que ajudam a reconstruir os fatos e fenômenos urdidos no tempo histórico rememorado.

No alcance do objetivo e para "responder" às questões elencadas, trilhamos os pressupostos teórico-metodológicos da História Oral, que se constituíram em fontes orais ricas, e que contribuíram, de forma indelével, para a reconstrução dos 
acontecimentos passados relacionados à Educação de Adultos (EDA)7 e de Jovens e Adultos (EJA), tão vilipendiados no contexto alagoano em geral; e no sertanejo em particular, fato já constatado pelas pesquisadoras Moura e Freitas (2007) desde a primeira pesquisa realizada no campo da história e memória. Segundo as estudiosas, em Alagoas há um descaso com a memória escrita, o que acaba dificultando o acesso às informações valiosas que poderiam lançar luz sobre as práticas e experiências do passado educacional alagoano. Dificuldade também enfrentada por nós, quando passamos a escavar os cenários em que as ações do PEl foram desenvolvidas no sertão do Estado referido.

Nessa perspectiva, assim como no ofício do arqueólogo foi preciso escovar as pistas que vinham à tona, mediante incursões realizadas na comunidade sertaneja de Santana do Ipanema, e também seguimos os rastros deixados pelos estudos de Silva (2013, 2018) que nos antecederam e que deixou muitos caminhos por onde passamos a percorrer, considerando o interesse específico da pesquisa em localizar os sujeitos que tinham estudado no $\mathrm{PEI}$ e que tivessem dado continuidade aos estudos, ao longo das suas vidas. A curiosidade epistemológica por compreender esses trajetos tem relação com a necessidade de preservação da memória, sobretudo das pessoas comuns (BENJAMIN, 1994) que, na maioria das vezes, são esquecidas pelas grandes narrativas historiográficas.

Baseamo-nos no entendimento do historiador Walter Benjamin (1994) que destaca a importância de "escovar a história a contrapelo". Ou seja, escutar os que são relegados ao silenciamento, aqueles cujas vozes são menosprezadas por pertencerem às classes populares, vistos como sujeitos sem cultura, ou possuidores de uma cultura menor, isto é, sem valor social. É que, historicamente, a cultura popular foi interpretada como uma manifestação sem caráter técnico,

\footnotetext{
${ }^{7}$ A oferta de educação para os sujeitos analfabetos, notadamente os adultos, iniciou com as campanhas nacionais em 1947, e tinham como perspectiva "erradicar" o analfabetismo, sendo, estas classes de alfabetização, conhecidas por Educação de Adultos (ADA), sentido ainda interposto no título das Conferências Internacionais de Educação de Adultos, as Confintea que iniciaram as ações em 1949. Somente a partir da década de 1980, com o aumento da presença dos jovens nas turmas noturnas, resultado das sucessivas reprovações na escola diurna, é que se passou a reconhecer estes espaços como também dos jovens, mudando a nomenclatura para Educação de Jovens e Adultos.
} 
e por isso, desprendida de qualquer prestígio social. Destarte, escovando as práticas do PEI a contrapelo, observamos como, numa época marcada pela negação do direito à educação, os sertanejos se reapropriaram das ações pedagógicas ofertadas no período. $E$ conseguiram continuar estudando em fases posteriores, fato que lhes permitiu vivenciar outras interações diferentes das que lhes tentaram conformar, levando em conta a realidade sertaneja no recorte histórico estudado (1973-1985).

É importante dizer, ainda, que as entrevistas com os interlocutores não se esgotaram em si, porque a metodologia da História Oral ensina a valorizar vários documentos históricos, que são garimpados e utilizados como fontes primordiais para aguçar as lembranças, vez ou outra contestadas ou acompanhadas por lapsos de esquecimento. Para Pollack (1992, p. 4), isso ocorre por que "a memória é seletiva. Nem tudo fica gravado. Nem tudo fica registrado".

Compreendemos, também, que uma das maiores riquezas da História Oral assente no "[...] estudo das formas como pessoas ou grupos efetuaram e elaboraram experiências, incluindo situações de aprendizado e decisões estratégicas" (ALBERTI, 2018, p. 165). Essa afirmação é importante, uma vez que situa um dos princípios do fazer historiográfico que toma a oralidade como fio condutor. Isto é, buscar nas vozes dos sujeitos que vivenciaram ou partilharam determinado acontecimento, a sua reconstrução parcial por meio da narrativa. Foi esse processo que tentamos também perceber no estudo realizado, e do qual trazemos um recorte, elegendo duas narrativas, de dois egressos do PEl, que entrevistamos no mês de janeiro do ano de 2020.

Este artigo estrutura-se em duas partes. Na primeira, comentamos acerca do contexto - sertão de Santana do Ipanema-, e do lócus - Programa de Educação Integrada -, respectivamente, apontamos as principais características deste e delineamos suas linhas de atuação segundo a ideologia da época em que foi implementado. Na segunda parte trazemos a caracterização dos sujeitos, ao discutimos, a partir dos estudos da memória e da oralidade, seus percursos e configurações familiares na época, na tentativa de analisarmos em que medida o PEI contribuiu, ou não, 
para o processo de escolarização dos sertanejos. Ao passo que apontamos os sentidos que estes, após mais de 40 anos, atribuem àquela experiência educativa. Por fim, tecemos as considerações finais.

\section{CONTEXTO E LÓCUS DA PESQUISA}

Em Alagoas, chega-se à década de 1970 - recorte de estudo desta pesquisa - com o predomínio da produção da cana-de-açúcar e o domínio da hierarquização histórica que excluía as pessoas menos favorecidas. A educação escolar para os pobres permanecia como algo longe de ser alcançado. Verçosa (2006, p. 87) apresenta dados que demonstram o descrédito para com o ensino público: "No início dessa década [1970], com uma população de 310.000 habitantes, Alagoas contava com um contingente escolarizável de 78.470 crianças e jovens, dos quais apenas 9.483 frequentavam escola".

Os números não revelam o contingente de pessoas "não escolarizáveis", ou seja, adultos e idosos que em nenhum momento de suas histórias passaram pela educação escolar, sobretudo os menos favorecidos que povoavam o sertão do estado. Para muitos desses, as iniciativas de alfabetização de jovens e adultos implantadas pelo Mobral configuraram-se como a primeira oportunidade de frequentar espaços escolares, como demonstra a pesquisa de Silva (2013).

Nas pesquisas que o Grupo Multieja vem realizando desde 2011, e tendo como contexto os sertões de Alagoas, e há a preocupação acentuada em romper com a concepção de sertão datada e veiculada nos mais diversos meios de comunicação, literatura, cinema, e também o sentido léxico que o próprio dicionário construiu. Isso porque, ocasionalmente, a visão que se tem é a de um lugar seco, atrasado, erguido sob a plataforma da miserabilidade do seu povo - o sertanejo. Optamos, assim, por estudar o sertão a partir da sua pluralidade de vozes (MELO, 2006) e culturas, no sentido de perceber suas mudanças e mutabilidades pelas quais vem passando ao longo dos anos, sobretudo com o advento da globalização.

Entendemos, com base em Albuquerque-Júnior (2014) que pensar o sertão arcaico, é não o reconhecer como histórico e, 
portanto, distante das representações contemporâneas de tempoespaço-lugar. Por isso, reconhecemos que é preciso projetar para longe a visão que enxerga o sertão como a-histórico. E nesse sentido, tramar outros fios que se urdem às diversas práticas culturais e que rompem a ideia de estagnação. Albuquerque-Júnior (2014, p. 54) alerta, ainda, que pensar o sertão nesse sentido, não implica esquecer seus outros tempos, pois ser contemporâneo é:

[...] conter todos os tempos e fazê-los atualizar-se e modificar-se no presente que passa, lançando-se sem medo na abertura do devir que promete outros tempos futuros, possíveis, imprevisíveis; um sertão disposto a deixar de ser o que vem de longe para ser o que vai para longe de si mesmo, um sertão distante de si mesmo.

A citação é reveladora de muitas questões. Uma delas nos inspira a pensar os sertões contemporâneos, e está relacionada ao que postula Guimarães Rosa (2001) quando diz que o sertão está em toda parte. Nos parece que ambos os autores referidos convergem no sentido de pensar o sertão implicado num campo simbólico. Ou seja, que está enredado, antes de tudo, nas pessoas - as que, por meio das suas ações, dão sentido ao lugar - entendendo esta categoria como significativa de pertencimento. Assim, quando o sertão deixa de ser o que vem de longe - algo fora de si e de contexto e, portanto, isolado -, e projeta uma visão de instante, do agora, passa a revelar, também, suas matrizes histórico-contemporâneas, e anuncia as mutações que vêm sofrendo mediante sua austeridade socioantropológica (LINDOSO, 2011).

Nesse sentido, os escritos do historiador francês Michel de Certeau (2011), sobretudo os relacionados aos cotidianos e aos sujeitos ordinários, contribuíram, na mesma proporção, para entendermos o povo sertanejo como sujeitos ativos e recriadores, que por meio das artes de fazer, não aceitam com benevolência as imposições culturais outorgadas pela chamada "cultura erudita". Pelo contrário, os vimos como homens e mulheres que (re)criam, anonimamente, as suas existências, a partir dos artefatos que estão 
ao seu alcance. Concordamos com o autor quando alerta para o fato de que "não se deve tomar os outros por idiotas", é que:

Nesta confiança posta na inteligência e na inventividade do mais fraco, na atenção extrema à sua mobilidade tática, no respeito dado ao fraco, sem eira nem beira, móvel por ser assim desarmado em face das estratégias do forte, dono do teatro de operações, se esboça uma concepção política do agir e das relações não igualitárias entre um poder qualquer e seus súditos (CERTEAU, 2011, p. 70).

Assim é que, como habitantes do lugar-sertão, os sujeitos se constituem em "testemunhas oculares" e, ao mesmo tempo, protagonistas dos acontecimentos históricos, por meio dos quais faz o sertão ser outro, diferente do que vinha sendo, e ao mesmo tempo projetando para longe a visão de "matutos". Desse modo, nos dirigimos na contramão dos discursos ora construídos, como já citado, e passamos a compreender os sertanejos como aqueles que mobilizam táticas, e agem em meio ao campo minado do poder que, estrategicamente, tenta impedir essa mobilidade. O poder, o forte e as estratégias, segundo Certeau (2011), pertence às instituições, enquanto que as táticas, ou seja, as mil e uma maneiras de ocupar um espaço são operadas no campo do fraco, os passantes comuns, os heróis anônimos, os poetas dos próprios negócios - os sujeitos da pesquisa.

Abrimos um espaço para dizer que, com base no entendimento acima, é que temos percorrido o sertão de Santana do Ipanema em busca de informações que nos ajudem a reconstruir o fato investigado, qual seja: como os sujeitos experienciaram, nas décadas de 1970 e 1980, as ações do Mobral, especialmente as do PEl. O tempo verbal está sendo utilizado no presente "temos", pois o Grupo Multieja, incessantemente, vem buscando mediante uma trilha de pesquisas, compreender a história da Educação de Adultos e de Jovens e Adultos em diversas localidades de Alagoas. Os sertões do Estado, nesse caso, vêm sendo explorado por membros do Grupo que têm interesses particular nessa área geográfica, e no objeto relacionado à história e memória - uma de suas Raízes Rizomáticas. 
Nessa perspectiva, conforme mencionamos o lócus deste estudo foi o $\mathrm{PEl}$, que se constituiu na época, diante da carência por escola em Santana do Ipanema, enquanto um divisor de águas, e permitiu o acesso de muitos sertanejos que não tinham concluído o então ensino primário - denominação da época. Vale ressaltar, ainda, que o PEl foi o segundo Programa implementado pelo Movimento Brasileiro de Alfabetização (Mobral). Esse Movimento chegou ao contexto sertanejo, assim como em outras localidades, por meio de convênio com a prefeitura. Inicialmente, propôs classes de alfabetização, por meio do Programa de Alfabetização Funcional (PAF), sem especificação de locais para que fossem desenvolvidas as atividades. Nesse sentido, muitas dessas classes funcionaram nas próprias casas dos alfabetizadores ou em outros lugares improvisados.

Considerando o sucesso do PAF, o Mobral implantou o Programa de Educação Integrada (PEI), que começou a desenvolver suas ações no município de Santana do Ipanema em meados da década de 1970, e contou com uma exímia organização didáticopedagógica e administrativa, sendo responsável pela formação primária de diversos sertanejos. O PEl, diferente do PAF, desenvolveu suas ações em prédios escolares existentes - marcando-se como parte da educação dos municípios -, concentrando-se na Escola Ormindo Barros, e no Grupo Escolar Padre Francisco Correia ${ }^{8}$. Esse período vai ser definidor de um grande marco para a cidade, haja vista as restritas condições educativas.

$\mathrm{Na}$ instância da legislação, O PEI ancorou-se no Parecer 699/1972 do Conselho Federal de Educação (CEF), documento baseado no capítulo IV da Lei 5692/1971, cuja relatoria foi do Conselheiro Valnir Chagas, e que instituiu o Ensino Supletivo, ao destacar para o mesmo, quatro funções, a saber: suplência, suprimento, aprendizagem e qualificação.

A suplência [tem] como função 'suprir a escolarização regular para os adolescentes e adultos que não a tenham seguido ou concluído na idade

\footnotetext{
${ }^{8}$ Primeiras escolas estaduais construídas em Santana do Ipanema, sendo a primeira na década de 1930, e a segunda, em 1950.
} 
própria'. O suprimento [...] é a função de 'proporcionar, mediante repetida volta à escola, estudos de aperfeiçoamento ou atualização'. A aprendizagem é a 'formação metódica no trabalho', a cargo das empresas ou de instituições por estas criadas e mantidas. A qualificação baseiase obrigatoriamente em cursos, e não apenas em exames, e visa eletivamente à profissionalização. (BRASIL, 1972, p.306-307, grifos nossos)

A lógica da suplência é a compensação de uma escolaridade "perdida", não finalizada na "idade certa", pelos adolescentes e adultos, enquanto, que se previa, por meio do suprimento, que os sujeitos retornassem à escola, repetidas vezes, no intuito de se atualizarem. Entretanto, as intenções políticas, sobrepostas no Parecer, é a busca por uma aprendizagem e qualificação para o trabalho, organizada e dirigida, por empresas, sobretudo do setor privado. A população atendida era a economicamente ativa, capaz de aprender, metodicamente, no trabalho. Nesse sentido, observa-se a ideia de preparação de adolescentes, jovens e adultos para que estes pudessem contribuir para o desenvolvimento do país, que passava por um período de mudanças no setor industrial com a chegada das empresas multinacionais.

O PEI, no contexto das funções criadas pelo Parecer 699/1972, insere-se na função de suplência, pois tinha como objetivo primário compensar a escolarização daqueles que não tivessem concluído o nível primário - terminologia da época para os anos iniciais do Ensino Fundamental como o conhecemos a partir da Lei 9.394/96. Após a conclusão dessa etapa escolar, os alunos poderiam prosseguir no ensino dito "regular".

Essa característica aparece no referido Parecer como "circularidade de estudos", processo pelo qual se estabeleceu uma preocupação em "[...] eliminar tabiques e criar amplas vias de acesso entre níveis, graus e modalidades de escolarização [visando] o trânsito do Regular ao Supletivo e deste àquele" (p. 322-323), o que nos pareceu a tentativa ou a estratégia positiva que permitiu muitas pessoas continuarem seus estudos até o nível superior. $O$ que não aconteceu em Alagoas, porque o Conselho Estadual de Educação à época, não regulamentou. 
Uma questão nos parece ser central no PEl: a busca por maior integração dos sujeitos no meio social, no sentido de obterem cada vez mais autonomia dentro do sistema para que pudessem consumir e produzir, o que permitiria o desenvolvimento local. Isso vai ao encontro do que diz Freitag (1980, p. 92) que,

O Mobral, como se sabe, não é o primeiro esforço alfabetizador. Mas é a primeira vez que o governo se encarrega de implantar um movimento que alfabetize a força de trabalho e eleve, mesmo que por um mínimo, o seu nível de qualificação.

Nesse sentido, é possível observar que as secretarias estaduais e municipais que faziam convênio com o Mobral, no sentido de desenvolverem os respectivos Programas, recebiam materiais didáticos, a exemplo de cartilhas - para a alfabetização, que continham as palavras que chamavam de geradoras. Vale lembrar que o referido Movimento se apropriou, indevidamente, do processo metodológico desenvolvido pelo educador pernambucano Paulo Freire, que no final da década de 1950, defendeu em âmbito nacional, projetos de Educação Popular, nos quais, o percurso da alfabetização se daria, também, considerando o desenvolvimento da consciência crítica.

E que durante o período autocrata, resultante do Golpe de 1964, foi exilado por quase duas décadas. Assim, a Palavra Geradora, "grávida de mundo" como dizia Freire (1987) foi esvaziada do seu sentido político, e instituído um significado universal para as mesmas, tendo em vista a repressão da época.

Conforme destaca Jannuzzi (1975, p. 63), o equívoco estava na técnica de preparação do material de alfabetização que era "[...] confeccionado por uma equipe central para ser usado em todo território nacional". Ato que revelava a concepção "bancária" da educação, criticada por Freire (1987, p. 67) por se tratar de uma "[...] doação dos que se julgam sábios aos que julgam nada saber".

Em contrapartida, o PEI se configurou pelo seu forte caráter pedagógico - contar com os professores dos quadros dos municípios ou do estado - e institucional - instalar as suas turmas nas escolas -, fato este que, no nosso entendimento, lhe rendeu um alcance social 
de prestígio em relação, sobretudo ao PAF, pois suas ações ficaram, na primeira fase, sob responsabilidade das secretarias de educação; o que permitiu com essa atitude a ampliação de atendimento da faixa etária das instituições escolares locais que até então atendiam somente crianças.

Para tanto, operavam com os recursos financeiros advindos dos convênios firmados com o Mobral Central e com isso garantiam materiais de uso escolar necessários à operacionalização do trabalho docente, que eram distribuídos às escolas, além de contar com um amplo acervo didático, a exemplo do livro do aluno intitulado "Boa pergunta", impresso pela editora Abril S.A.

Inferimos, desse modo, que com a população ávida por escola, consideramos que o PEI foi logo legitimado pelos sertanejos que encontraram possibilidades concretas de acesso à escola, e graças à sua institucionalização, que propagou sua existência em alguns municípios mesmo após a extinção da Fundação ao qual pertencia. Consideramos, assim, que o acesso à escola fez com que muitas vidas fossem transformadas no contexto sertanejo, tendo em vista as configurações familiares da época - tema do próximo item.

\section{OS SUJEITOS DA PESQUISA - SERTANEJOS HERÓIS ANÔNIMOS}

Entendemos os sujeitos da pesquisa na perspectiva que nos diz Certeau (2011, p. 57): como "heróis anônimos", pensantespraticantes, possuidores de uma cultura "ordinária", esboçada nas suas maneiras de fazer, e que "[...] pouco a pouco ocupa o centro de nossas cenas científicas". Além disso, os vemos como sujeitos que se reapropriaram de uma experiência escolar específica - única - e conseguiram desenvolver-se, por meio de outras interações, ao longo da vida.

No trabalho de campo situamos a memória das pessoas como um cabedal infinito de recordações, que são evocadas no presente e carregadas de significados, atribuídos pelas percepções que se têm quando estas veem à tona. Concordamos com Bosi (1994), quando nos alerta para a impossibilidade do "resgate" dos fatos passados, 
tendo em vista o tempo em que ocorreram, e as mudanças pelas quais as pessoas passaram no decorrer deste.

No movimento de idas e voltas ao campo, no realizar das entrevistas com pessoas que partilham experiências comuns de um determinado acontecimento, entendemos que quando o gravador era desligado, o sentimento era do não inacabamento - próprio dos seres humanos -, que poderiam falar por horas sobre suas interações com o mundo. É que aprendemos com Portelli (2016) que esse sentimento decorre da relação estabelecida entre entrevistado e entrevistador, que passam a dialogar mutuamente.

Escutar para contar - esse foi um dos princípios que permeou nosso trabalho. Além disso, estivemos atentos à questão ética que alude para o necessário respeito ante às memórias dos sujeitos narradores, que as confidenciaram de forma dialógica, na ocasião da entrevista. Nesse sentido, percebemos, ao escutar de forma sensível que a figura do narrador ia se confundindo com a de um tecelão, que com os fios da memória foi urdindo as tramas dos fatos históricos que fizeram parte da sua experiência de vida, ao atribuir sentidos. Fios esses que nos ajudaram na tessitura deste artigo.

Assim, o primeiro passo foi o acesso aos arquivos presentes na Secretaria Municipal de Educação, órgão local que guardava um acervo importante de documentos, que nos ajudaram no mapeamento dos interlocutores. Diante do referido arquivo fomos tomados pelo sentimento que Farge (2017, p. 20) descreve como "solidão", face à sua desmesura, isto é, "uma solidão em que pululam tantos seres 'vivos' que parece quase impossível dar conta deles, ou seja, fazer sua história".

Os nomes dos homens e mulheres sinalizavam muitas memórias, que dariam acesso a histórias plurais, e acontecimentos ímpares que denotavam a existência da vida cotidiana, bem como das "políticas de agir" (CERTEAU, 2011) das pessoas "ordinárias", dos passantes comuns, e que são representadas pelas grafias nos documentos. Nomes que levam a sujeitos, personagens históricos, pertencentes a configurações familiares específicas dentro de um contexto social, que em tempos de outrora, fora palco de muita resistência e trabalho, sobretudo pelo fato de estar localizado em terras cercadas pelo poder dos coronéis. 
Com base no exposto, entendemos o arquivo, também, como uma janela aberta para o mundo (FARGE, 2017), onde conseguimos enxergar os fatos e acontecimentos de tempos remotos mediante a luz que entra nesse espaço, iluminando e esquentando os já frios papéis empilhados. Essa sensação esteve sempre presente, e à medida que encontrávamos um sujeito, era como se tivéssemos localizado um diamante, inspirados em Bosi (1994), quando diz que uma lembrança é um diamante que vai sendo lapidado pelo espírito.

Desse modo, de posse dos documentos e papéis soltos, saímos em busca dos nomes que estavam grafados nas muitas prestações de contas, nos convênios, nas atas finais das turmas, de modo que tivemos sucesso em muitas ocasiões. Enquanto que em outras, fomos surpreendidos por informações que não se confirmaram, o que nos deixou apreensivos, dada a intensidade com que nos dispomos a localizar os sujeitos. Esses fatos não nos desanimaram, ao passo que sempre reinventávamos os caminhos.

Depois de muitas buscas, conseguimos entrevistar 13 sujeitos (ex-supervisoras, ex-professoras e ex-alunos), dos quais utilizamos, nos limites deste artigo, a narrativa de 2 egressos do PEl, que continuaram os estudos ao longo de suas vidas, os quais chamamos pelos nomes fictícios de Marcos e Januário. Ambos estudaram na cidade de Santana do Ipanema, o primeiro na década de 1970 e o segundo na década de 1980. O encontro com os mesmos se deu em dia e horário marcados, após fazermos os primeiros contatos para a apresentação da pesquisa, e dos objetivos que tínhamos delineados.

O Sr. Marcos tem 58 anos, é aposentado e mora em Santana do Ipanema com sua esposa e sogro. O encontro com ele deu-se por meio da sua esposa que, ao saber da pesquisa, informou que seu marido tinha realizado os estudos no PEl. À medida que tivemos a confirmação, marcamos dia e horário para realizarmos a entrevista acontecida na residência do nosso interlocutor. A sua narrativa trouxe muitos elementos contextuais, principalmente relativos à sua vida $\mathrm{e}$ dos vários movimentos que teve de fazer para manter-se estudando. Assim, narrou que:

[...] tinha aproximadamente uns quinze anos, tinha iniciado meus estudos lá no sítio, quando eu cheguei 
na segunda série, concluí a segunda série, aí meus pais me incentivaram a estudar e como no sítio naquela época não existia condições nenhuma de se estudar, aí [...] eles me incentivaram a estudar na cidade (Sr. Marcos, egresso do PEI).

Ao revolver suas memórias o narrador nos mostrou as dificuldades para prosseguir estudando num contexto que não ofertava condições estruturais. Viveu toda sua infância na zona rural, e assim como outros sujeitos da sua localidade, esteve à margem da escola, uma vez que, as poucas unidades existentes não ofertavam todas as etapas escolares. O pai e a mãe - principais componentes da sua configuração familiar -, tinham a concepção de que a escola possuía a função de apenas ensinar a ler, e escrever uma carta, e por essa razão o matriculou, tardiamente, como nos confidenciou:

Naquela época, o pessoal do sítio tinha uma mentalidade um pouco diferente de hoje, [o] que é que meus pais diziam e as pessoas até mais antigas: colocava os filhos na escola só para aprender a escrever o nome e ler uma carta e fazer uma carta. Aí não tinha interesse em colocar novinho só; não adiantava pra eles, porque ia aprender novinho e num ia nem... então deixava mais pra frente, quando tivesse uma certa idade, porque só ia mesmo aprender fazer o nome e então fazer uma carta, fazer uma carta, aí eles resolveram me colocar na escola quando eu já tinha 11 anos de idade (Sr. Marcos, egresso do PEI).

Por muito tempo perdurou a tese de que "gente da roça não precisa estudar", pois a funcionalidade da leitura e da escrita não estava ao alcance do pobre. No caso do narrador o que se observa é que essa premissa foi levada em consideração pelos pais até certo ponto, considerando que à medida que Sr. Marcos teve acesso à escola, seus genitores despertaram-se para outras perspectivas. A exemplo da sua permanência e para isso o deslocaram para "estudar na cidade". Assim, entendemos, conforme nos alerta Lahire (2011, p. 14) que: "o carácter historicamente construído das desigualdades não implica que a sua desconstrução seja uma operação fácil". Pois, 
muitos sujeitos, segundo o mesmo autor citado, não acreditam que existam outros lugares em que possam manter interações, fora dos seus círculos familiares e das suas próprias condições de existência.

A trajetória de Marcos no Programa de Educação Integrada iniciou na $3^{a}$ série do ensino primário - terminologia da época - e após concluir essa etapa escolar continuou os estudos na escola dita regular. Pois o Mobral, por meio dos seus Programas, a exemplo do PAF e do PEl, se apropriou da possibilidade de "circularidade de estudos", presente no Parecer 699/1971 - como comentamos -, no qual o aluno concluinte da $4^{\mathrm{a}}$ série poderia prosseguir em qualquer outra escola.

O que permitiu ao Sr. Marcos continuar, cursar e concluir o Curso Técnico Integrado em Agropecuária na Escola Técnica de Satuba que passou a ser Instituto Federal de Alagoas (IFAL). Ele exerceu por muitos anos a função de Técnico Agrícola na Secretaria da Agricultura do Estado de Alagoas e depois foi lotado na Agência de Defesa e Inspeção Agropecuária de Alagoas (Adeal), onde se aposentou.

É importante ressaltar que o egresso teve o apoio irrestrito dos pais, e de outros familiares, que o aconselham a migrar para Santana do Ipanema, e depois, para a cidade de Satuba, a fim de concluir a escolaridade e também adquirir uma formação técnica. Sabemos, nesse caso, que as condições de existência dos indivíduos, são, antes de tudo, as condições de coexistência (LAHIRE, 1995). Fato que interpretamos como sendo positivo no contexto de vida de Marcos pois, quando indagamos sobre as possibilidades de cursar o nível superior, nos disse que os recursos materiais acabaram, mas enfatizou: "[...] ali [no PEI] já me deu um suporte muito grande. Um incentivo pra continuar" (Sr. Marcos, 58 anos), de modo que o alcance de outras interações só foi possível, segundo o interlocutor, pela passagem que tivera pelo referido Programa.

Já o Sr. Januário tem 56 anos, e mora em um distrito próximo de Santana do Ipanema. O encontro com ele deu-se após muitas buscas e com a ajuda de pessoas da comunidade, que se juntaram a nós, conforme tomaram ciência da nossa pesquisa. Recebemos a notícia de que um morador do local tinha sido indicado por uma exprofessora - que não se constituiu interlocutora dessa pesquisa pelo 
fato de residir em São Paulo e manter contato, via telefone, com pessoas próximas e confidenciou essa pista valiosa. Conforme já referido, todas as entrevistas eram agendadas com antecedência dentro dos dias e horários que melhor se adequavam aos interlocutores.

Dessa maneira, o Sr. Januário nos recebeu em sua casa em um dia de domingo. Inicialmente contou, assim como o Sr. Marcos, das dificuldades em permanecer estudando na sua época de infância e adolescência. Bastante emocionado disse que quando criança enfrentou a dureza do pai em relação à criação e sua visão sobre a escola. Em tom de desabafo narrou:

Meu pai era um pouco meio duro, porque parece que meu pai queria que a gente fosse trabalhador para ele a vida inteira, parece que ele não queria que a gente crescesse na vida. Eu tenho a pensar isso porque na escola de dia [horário diurno] ele, ele não deixava a gente estudar, muitas vezes, você tava com a roupinha, com a fardinha para ir para escola [e] ele mandava tirar a roupinha para ir para roça: 'Não, não vai para a escola, tira a roupa, vai trabalhar' (Sr. Januário, egresso do PEI).

O relato de vida do interlocutor focalizou a realidade vivida por muitos sertanejos, que enfrentavam a necessidade do trabalho diário na roça em busca da sobrevivência familiar. Os filhos, nesse cenário, principalmente os meninos, tinham como tarefa "ajudar" na labuta do campo, enquanto as meninas contribuíam em casa, nos afazeres domésticos. A dureza da vida, e o trabalho na roça embaixo do sol escaldante é uma marca forte nas narrativas dos egressos, que com recorrência tinham seus sonhos "mutilados" em razão das necessidades impostas pela condição da vida. O trabalho realizado pelas crianças não se diferencia dos adultos, de modo que as tarefas exigiam muito esforço físico, fato que provocava cansaço extremo e impedia que frequentassem a escola em outros horários. A atitude de estudar era, por vezes, um ato de coragem, como nos disse o Sr. Januário: 
[...] então à noite eu fui forçado porque eu disse: Não, agora eu vou estudar porque eu estou com 15 anos, eu vou estudar, eu vou à noite. E, muitas vezes, eu saía do Aricuri [sítio em que morava] aqui é, uns 5 ou $6 \mathrm{~km}$. Ele [pai] largava [do trabalho] 17h30 e 19h eu tinha que estar na escola e, muitas vezes, eu ia correndo com os meus irmãos, meus irmãos pequenos e eu ia pegando na mão deles (Sr. Januário, egresso do PEI).

Após esse período no $\mathrm{PEl}$, o narrador deu seguimento aos estudos tempos depois. Ele o interrompeu aos 18 anos, para se juntar aos contingentes de migrantes nordestinos com destino a São Paulo, onde morou por 10 anos. As experiências de trabalho que teve, na capital paulista fez com que sentisse a necessidade de estudar. Pois perdeu muitas oportunidades de "crescer" no trabalho, por só possuir o ensino primário, fato que lembra bem e se orgulha de possuí-lo. Ao retornar para a cidade de Santana do Ipanema, ele deu continuidade por meio do Ensino Supletivo, e pelo qual concluiu a escolaridade através de exames. Mas fora enfático ao dizer que: "[...] tudo graças à Educação Integrada, o melhor ensino que eu já tive".

Vale ressaltar que a configuração familiar do egresso Januário é muito distinta da apresentada por Marcos. Enquanto este tinha apoio, aquele foi impedido, muitas vezes, de frequentar a escola, denotando que, sobretudo o pai, não tinha legitimado a escola como um espaço de sociabilidade e de aprendizagens, e deu a entender que $\circ$ melhor lugar era $o$ trabalho na roça, pois garantia a sobrevivência.

Compreendemos, nesse sentido, que em algumas ocasiões,

[...] o que não é objectivamente acessível não passa a ser subjectivamente desejável e acabamos por gostar apenas do que a situação objectiva nos permite gostar, ou seja, não tomar os seus desejos por realidade, mas a realidade dos possíveis pelos seus desejos mais pessoais (LAHIRE, 2011, p. 15).

Nos parece que a escola, para o pai do interlocutor, na época em que estudou no $\mathrm{PEl}$, era algo que não estava "objectivamente acessível". Nesse caso, passou a também não ser desejada de forma 
subjetiva, o que o fez tomar a realidade como ponto concreto e de ancoragem, limitando, dessa forma, os filhos.

Isso nos faz recorrer ao alerta do pesquisador citado acima,

A família, através da qual cada indivíduo aprende a descobrir o mundo social e a encontrar o seu lugar, é o primeiro espaço (primário) que tende a estabelecer objectivamente - sem o saber ou pretender - os limites do possível e do desejável (LAHIRE, 2011, p. 14).

Inferimos, assim, que os limites da configuração familiar de Januário não ultrapassavam o seu próprio lugar, ou seja, a roça. É tanto que ao trazer sua narrativa acima, de forma emocionada, relatou "Ele [o pai] não deixava a gente estudar, muitas vezes, você tava com a roupinha, com a fardinha para ir para escola [e] ele mandava tirar a roupinha para ir para roça: 'Não, não vai para a escola, tira a roupa, vai trabalhar" ".

É de se compreender que o Programa de Educação Integrada (PEI) foi um divisor de águas para os sujeitos da comunidade sertaneja, sem querer generalizar considerando as falas dos narradores egressos, que nos fazem acreditar que as possibilidades concretas de escolarização que se criara, com o PEl, naquele contexto, diante da escassez de outros espaços formativos fizeram com que muitos sertanejos participassem. A avidez por escola é sentida, narrada e exemplificada com uma intensidade que ultrapassa o simples argumento de acesso à escola, mas como um fato que permitiu a mudança de toda a vida.

Ressaltamos também que os percursos escolares dos sujeitos foram construídos por movimentos pendulares, como foi o caso do Sr. Januário, e também por linearidades, sem interrupções, a exemplo do Sr. Marcos. Eles mostraram, por meio de suas narrativas, que num contexto marcado pelas desigualdades, o permanecer estudando tinha o sentido de enfrentamento às injustiças sociais, na perspectiva de mudar de vida, e ainda o de sobrepujar os modos de existência e coexistência. 


\section{CONSIDERAÇÕES FINAIS}

Neste texto, que teve como objetivo analisar como os sujeitos sertanejos experienciaram as ações de escolarização implantadas pelo Mobral, especialmente as do Programa de Educação Integrada (PEI), ficou explícito que as trajetórias escolares dos sujeitos se deram considerando muitos fatores, sobretudo os condicionantes familiares, que em um caso - Sr. Marcos, apoiava a continuidade do percurso formativo, enquanto que em outro - Sr. Januário, impedia que o mesmo almejasse outros espaços de interações, notadamente a escola.

Por meio das narrativas nos foi possível compreender que, diante do contexto social da época (1970-1980) entrecortado pela sobrevivência, os sujeitos se apropriaram da "oportunidade" de acesso à escola, que se abria para eles naquele momento, e conseguiram mediante movimentos pendulares, permanecer, desafiando, assim, os marcadores sociais que tentavam conformá-los a uma ordem em que prevalecia as injustiças, especificamente a negação do direito de estudar. Na cidade de Santana do Ipanema$\mathrm{AL}$, a primeira escola iniciou suas atividades apenas em 1934, e mesmo assim, era de cunho privado, o que nos dá a entender que só estudavam lá quem possuía alto poder aquisitivo.

Consideramos que houve uma mobilização por parte dos sujeitos entrevistados, uma vez que mesmo o PEI tendo ficado concentrado na maior parte do tempo na zona urbana de Santana do Ipanema, os sertanejos moveram "esforços e paixões" no sentido de prosseguir em suas escolarizações, tendo em vista esse cenário crítico. Conseguiram se mover nesse terreno estratégico, minado, na medida em que tiveram que deixar seus lares, para morar na cidade em casas de parentes, e mesmo há aqueles que, mesmo após o dia de trabalho braçal, ainda encontravam forças para frequentar a escola.

O nosso interlocutor - Sr. Marcos -, explicitou ter sido significativa a presença de pessoas que o ajudaram, durante o percurso da sua escolaridade, que deu-se numa lógica complexa, e que envolveu: sujeito-família - que teve um papel fundamental na permanência escolar. Pois contribuiu ora provendo as condições 
materiais, ora simbólicas, através do apoio e incentivo; e a sociedade, sendo esta representada pelas interações criadas no transcurso das fases escolares, e que atua na construção das subjetividades e das relações de pertencimento.

Ao contrário do que aconteceu com o Sr. Januário, que não contou com o apoio dos membros da coletividade familiar, pois não compreendiam a legitimidade social da escola, como espaço educativo importante para a construção do ser. Entendemos que quando isso ocorre, é constituída uma barreira quase instransponível, e ocasiona muitas interrupções na escolaridade, como foi o caso do Sr. Januário, que após concluir os estudos no PEl, migrou para a cidade São Paulo em busca de melhores condições de vida. Ao mesmo tempo em que revela o autoritarismo do pai, e de como o mesmo impedia, quando na infância, de frequentar a escola, fato que o leva a classificar que durante esse período não conseguiu aprender.

As vozes de ambos entrevistados nos fizeram entender "as maneiras de fazer", mostraram que foram se reapropriando dos objetos que tinham à sua disposição e criaram formas próprias para se movimentar no campo social marcado por dispositivos regulatórios que buscavam conformar os sujeitos a uma dada

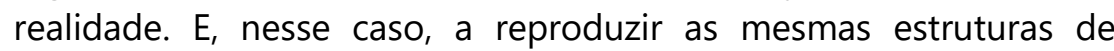
existência dos seus pais, por meio de discursos como: "estudar é para rico". Podemos dizer que as ações "microbianas" que realizaram assumem a característica daquilo que Certeau (1994) vai chamar de bricolagem. O sujeito bricolador transforma os artefatos que Ihe são apresentados em instrumentos táticos que o autoriza a caminhar pelos campos técnicos, desafiando os marcadores que tentam limitar a mobilidade.

Diante dessas oportunidades em um lugar carente como o sertão alagoano, as narrativas dos sujeitos, na rememoração de suas experiências, expressaram aceitação das ações do PEl; implementadas pelo Mobral nas décadas de 1970 e 1980 sem, no entanto, as situarem no contexto da Ditadura civil-militar, em plena vigência à época. A reconstrução de parte da história do PEI/Mobral foi possível a partir da recomendação de Walter Benjamin (1994): "a contrapelo", uma vez que, as narrativas elencadas aqui, originaram- 
se, sobretudo, de um exercício de escuta de pessoas comuns que, geralmente, não aparecem nos registros escritos oficiais.

\section{REFERÊNCIAS}

ALBERTI, Verena. Histórias dentro da história. In: PINSKY, Carla Bassanezi. Fontes históricas. 3. ed. São Paulo: Contexto, 2018.

ALBUQUERQUE JR., Durval Muniz de. Distante e/ou do instante: "sertões contemporâneos", as antinomias de um enunciado. In: FREIRE, Alberto (Org.). Culturas dos sertões. Salvador: EDUFBA, 2014. BRASIL. Parecer n 699/1972 C.E. de $1^{\circ}$ e $2^{\circ}$ Graus. Brasília, DF, Mec. 1972.

BRASIL. Lei $n^{\circ}$ 9.394, de 20 de dezembro de 1996. Estabelece as Diretrizes e Bases da Educação Nacional. Brasília, 1996.

BENJAMIN, Walter. Magia e técnica, arte e política: ensaios sobre literatura e história da escrita. 8. ed. São Paulo: Brasiliense, 1994. (Obras Escolhidas, v.1).

BOSI, Ecléa. Memória e sociedade: lembranças de velhos. 3. ed. São Paulo: Companhia das Letras, 1994.

CERTEAU, Michel de. A invenção do cotidiano: 1 Artes de fazer. 17. ed. Petrópolis: Vozes, 2011.

CERTEAU, Michel de. A invenção do cotidiano: 1 Artes de fazer. Petrópolis: Vozes, 1994

FARGE, Arlete. O sabor do arquivo. São Paulo: Editora da USP, 2017. FERRARO, Alceu Ravanello. História inacabada do analfabetismo no Brasil. São Paulo: Cortez, 2009.

FREITAG, Bárbara. Escola, estado e sociedade. São Paulo: Moraes, 1980.

FREIRE, Paulo. Pedagogia do oprimido. Rio de Janeiro: Paz e Terra, 1987.

GERMANO. José Willington. Estado militar e educação no Brasil (1964-1985). 5. ed. São Paulo: Cortez, 2011. 
JANNUZZI, Gilberta Martino. Confronto pedagógico: Paulo Freire e Mobral. São Paulo: Cortez, 1975.

LAHIRE, Bernard. Sucesso escolar nos meios populares: as razões do improvável. São Paulo: Ática, 1995.

LAHIRE, Bernard. A transmissão familiar da ordem desigual das coisas. Sociologia, Revista da Faculdade de Letras da Universidade do Porto, v. 21, p.13-22, 2011,

LARROSA, Jorge. Notas sobre a experiência e o saber da experiência. In: LARROSA, Jorge. Tremores: escritos sobre experiência. Belo Horizonte: Autêntica Editora, 2016.

LINDOSO, Dirceu. 0 grande sertão: os currais de boi e os índios de corso. Brasília: Fundação Astrogildo Pereira, 2011.

MOURA, Tânia Maria de Melo; FREITAS, Marinaide. Educação de Jovens e Adultos em Alagoas: incursões na história das políticas ações e concepções em âmbito governamental (1960-1980). In: GRACINDO, Regina Vinhaes. Educação e diversidade: estudos em campos de desigualdades sócio-educacionais. Brasília: Líber Livro, 2007.

MELO, Adriana Ferreira. O lugar-sertão: grafias e rasuras. Dissertação. (Mestrado em Geografia) - Instituto de Geociências, Universidade Federal de Minas Gerais, Belo Horizonte, 2006.

POLLACK, Michael. Memória e identidade social. Estudos históricos, Rio de Janeiro, v. 5, n. 10, 1992.

PORTELLI, Alessandro. História oral como arte da escuta. São Paulo: Letra e Voz, 2016.

ROSA, Guimarães. Grande sertão: veredas. Rio de Janeiro: Nova Fronteira, 2001.

SILVA, Jailson Costa. O Mobral no sertão alagoano: das histórias e memórias às sínteses possíveis após quatro décadas. 2013. 153 f. Dissertação (Mestrado em Educação) - Universidade Federal de Alagoas, Maceió, 2013. 
SILVA, Jailson Costa. A memória dos esquecidos: narrativas dos sujeitos partícipes das ações do Mobral Cultural no sertão de Alagoas. 2018. 229 f. Tese (Doutorado em Educação) - Centro de Educação. Programa de Pós-Graduação em Educação, Universidade Federal de Alagoas, Maceió, 2018.

VERÇOSA. Elcio de Gusmão. Cultura e educação nas Alagoas: histórias, histórias. 4. ed. Maceió: EDUFAL, 2006.

Submetido em: Julho/ 2021.

Aceito em: Agosto/ 2021. 